\title{
Henri Nonn, 1929-2017 : quand l'Alsace perd son géographe de référence
}

\section{(2) OpenEdition}

Journals

Édition électronique

URL : http://journals.openedition.org/rge/6167

ISSN : 2108-6478

Éditeur

Association des géographes de l'Est

Référence électronique

«Henri Nonn, 1929-2017 : quand l'Alsace perd son géographe de référence », Revue Géographique de l'Est [En ligne], vol.57 / 1-2 | 2017, mis en ligne le 09 octobre 2017, consulté le 08 septembre 2020. URL : http://journals.openedition.org/rge/6167

Ce document a été généré automatiquement le 8 septembre 2020

Tous droits réservés 


\section{Henri Nonn, 1929-2017 : quand l'Alsace perd son géographe de référence}

C'est en 1965 que Henri Nonn a soutenu sa thèse d'État au sein de la Faculté des Lettres de Strasbourg, menée sous la direction de Jean Tricart et intitulée Les régions côtières de la Galice (Espagne) : étude géomorphologique. «Travail magistral » pour G. Viers. Pourtant, comme bien des morphologues de sa génération, $\mathrm{H}$. Nonn se dédie finalement à la géographie humaine, qu'il avait déjà abordée avec sa thèse de troisième cycle à propos des densités urbaines. En poste à Strasbourg, il investit un champ qu'il ne quittera jamais plus : le territoire, ou plutôt les territoires alsaciens, et cela durant une durée exceptionnellement longue pour un chercheur, puisqu'elle s'étend jusqu'à sa mort.

Henri Nonn aura connu l'âge d'or de la géographie aménagiste, depuis les années 1960 jusqu'au début des années 2000. En ces temps révolus, la puissance publique s'intéressait grandement à la prospective territoriale. Elle avait ses propres experts, mais, dans la logique initiée par le programme des «métropoles d'équilibre » de 1965, elle travaillait avec des universitaires engagés dans la géographie régionale. Ajoutons que l'université de Strasbourg disposait alors du Centre de Recherches Régionales qui avait pignon sur rue, avec Étienne Juillard (1914-2006) et Michel Rochefort (1927-2015) notamment, Centre que Henri Nonn avait lui-même dirigé en 1974. Il avait par la suite été président de l'Association de Prospective Rhénane (APR), fondée en 1987. Ainsi, pendant plusieurs décennies, Henri Nonn a tissé des liens, répandu du savoir et plus encore des idées entre l'État français, les collectivités, les universités et la société civile.

En 1974, dans la série Découvrir la France (Larousse), il avait pris à sa charge les huit numéros consacrés à l'Alsace et à la Lorraine. Son diagnostic introductif pour l'Alsace n'a pas pris une ride : «(...) Naît alors l'impression d'une terre opulente, où la gaieté s'allie au sérieux, fidèle aux traditions, mais ouverte au progrès, d'un pays auquel ses fils sont particulièrement attachés. En réalité, une analyse en profondeur montre que la richesse n'est pas également partagée sur son territoire, que le caractère jovial des habitants et leur goût de bien vivre masquent nombre de problèmes humains et psychologiques ; que la position du pays en « Finistère continental » de la France, et en 
même temps de "porte ouverte " sur l'axe rhénan n'est pas exempte de difficultés " (n³9, p.2). Et pour qui veut connaître l'Alsace d'aujourd'hui dans le détail, son ouvrage L'Alsace et ses territoires (2008) reste une somme irremplaçable de 576 pages.

4 En suivant le fil de ses publications, on découvre d'abord un géographe attentif au développement d'une croissance harmonieuse et respectueuse, promouvant une Alsace prospère grâce à son ouverture et son organisation interne faite de mille clivages subtils inscrits dans sa territorialité. Henri Nonn avait connu l'expansion des Trente Glorieuses et les ambitions aménagistes de la modernité; «les cohérences fonctionnelles et territoriales " étaient pour lui un cheval de bataille. Puis il a vu l'Alsace se repositionner avec la construction européenne, la régionalisation inachevée et les difficultés du monde contemporain. La métropolisation est devenue à la fois un facteur de croissance et de déséquilibre. Strasbourg est une métropole européenne, mais elle manque néanmoins de taille critique par rapport aux villes les plus brillantes. Adossé aux apports de statisticiens comme Bernard Aubry et d'économistes comme Jean-Alain Héraud, H. Nonn traque les pistes qui permettent la réussite de Strasbourg et, par effet d'entraînement, de l'Alsace comme des régions bordières. Et de démontrer que, pour « faire métropole " (Cahiers de l'APR, 2013, p.15), la recherche publique est une force motrice par rapport à celle d'autres métropoles. Mais il faut faire des choix : rechercher la spécialisation ou avancer en bloc? Et comment susciter davantage de cosmopolitisme et de créativité (c'est-à-dire, donner une valeur économique à la création) ? Mais en 2012, souligne-t-il, "la Région Alsace était impliquée dans un cluster d'industries créatives, Iconoval, dont elle a décidé (assez unilatéralement) la fermeture» (id, cf. p. 184). Il pointe également le risque que fait courir la métropolisation pour tous ceux qui «sont restés au bord du chemin " (id.). Et d'en appeler à une réflexion intimement géographique à trois échelles : Strasbourg, l'Alsace, le monde rhénan. Un univers qui ne recouvre pas les contours du Grand Est...

Les réalités concrètes constituent un pan important de l'œuvre de Henri Nonn, mais celle-ci a intégré des aspects conceptuels, en particulier avec le groupe RITMA (Recherches Interdisciplinaires sur les Territoires de Marges) (2001) qui avait lui-même rebondi sur Les économies industrielles de la France de l'Est (1995). On y découvre une profonde stimulation pour l'esprit, où l'Alsace sert de laboratoire pour la compréhension générique des territoires coincés entre des centres qui les surdéterminent. L'idée a percolé puisque, depuis deux ans, les futurs professeurs d'histoire et de géographie planchent sur la France des marges lorsqu'ils se présentent au Capes et à l'agrégation.

Raymond Woessner, Professeur de Géographie retraité, Paris Sorbonne 